\title{
Speciation and Mobility of Phosphate in the Eutrophic Ponds at Prospect Park, Brooklyn, New York, USA
}

\author{
Ying Liu, Zhongqi Cheng, Brett F. Branco, John F. Marra \\ Department of Earth and Environmental Sciences, Brooklyn College of the City University of New York, New York, USA \\ Email: ZCheng@brooklyn.cuny.edu
}

How to cite this paper: Liu, Y., Cheng, Z.Q., Branco, B.F. and Marra, J.F. (2017) Speciation and Mobility of Phosphate in the Eutrophic Ponds at Prospect Park, Brooklyn, New York, USA. Journal of Geoscience and Environment Protection, 5, 26-36. https://doi.org/10.4236/gep.2017.56004

Received: April 13, 2017

Accepted: June 9, 2017

Published: June 12, 2017

\begin{abstract}
The water system at the Prospect Park ponds of Brooklyn, NY has been receiving chronic loads of orthophosphate from the municipal water since the mid ' 90 s. The ponds are currently eutrophic with degraded water quality and high levels of $\mathrm{P}$ in the sediment. In this study, the distribution and speciation of $\mathrm{P}$ within the water column was examined. The dominant form of $\mathrm{P}$ in the water was found as soluble reactive phosphate (SRP) and the temporal change of SRP indicated significant internal loading from the sediment during late summer in the ponds downstream. Lake sediment was investigated for P fractionation and phosphate bound to Fe-hydroxides was the dominant form of $\mathrm{P}$ in the sediment. Both external and internal P pools are important and should be taken into consideration when planning for restoration.
\end{abstract}

\section{Keywords}

Phosphate, Eutrophication, Speciation, Nutrient Loading

\section{Introduction}

Eutrophication is the leading cause of water impairment for reservoirs and watersheds all over the world, especially in developing countries like China [1] [2] [3]. Excessive supply of nutrients (mainly of anthropogenic origin) could lead to the proliferation of plankton and algae, degraded water quality and thus limit water uses [3]. Phosphorus (P) is commonly regarded as the key variable and a limiting nutrient in freshwater reservoirs [2] [4] [5].

The man-made water system at Prospect Park in Brooklyn, New York, USA is composed of a series of connected shallow freshwater ponds built in late 19th century. These ponds are fed mainly by municipal water, vary in size and depth, 
and the flow is driven by elevation difference (Figure 1). These shallow ponds are currently suffering from eutrophic symptoms including the excessive growth of macrophytes and blue green algae. Since mid-1990's, the municipal water has contained on average $2 \mathrm{mg} / \mathrm{L}$ of $\mathrm{P}$ as orthophosphate. The phosphate $\left(\mathrm{PO}_{4}\right)$ is added as a common corrosion inhibitor [6] [7] [8] for the municipal water supply systems in the United States. As a result, on average four metric tons of $\mathrm{P}$ in the form of orthophosphate enters the aquatic system of New York City each year. The impacts of this excessive nutrient on the urban environment and ecosystems over the long term have not been adequately addressed.

Besides this direct chronic external source, $\mathrm{P}$ in the water column could also origin from lake sediments. Such internal loading has often been reported to contribute a large proportion of the bio-available $\mathrm{P}$ responsible for algal bloom. The sediment bound $\mathrm{P}$ could hinder the restoration of water quality even after the external nutrient loading is eliminated [9] [10]. The duration and extent of nutrient internal loading from sediment are related to lake conditions and the characteristics of the sediment. The potential for sedimentary phosphate release is generally investigated through chemical sequential extractions for speciation [11] [12]. In general, $P$ in the sediment can be categorized into: labile or exchangeable $\mathrm{P}$ [13] [14]-P associated with $\mathrm{Fe} / \mathrm{Mn}$ and $\mathrm{Al}$ hydroxides or oxides especially $\mathrm{FeOOH}$ [15], $\mathrm{P}$ in Ca-bound compounds or apatite-P [16] [17], and Organic-P, the mobility of which is complex and not well understood.

There are multiple processes which could lead to the release of $P$ from sediments. Among the various key factors, Oxidation-Reduction Potential (ORP), Dissolved Oxygen (DO), $\mathrm{pH}$, microbial processes and temperature appear to be the most important, although the impacts of each are often lake specific [18] [19]. For example, one typical process in productive lakes is that with lowered redox potential near the sediment water interface, $\mathrm{Fe}$ complex within the sedi-

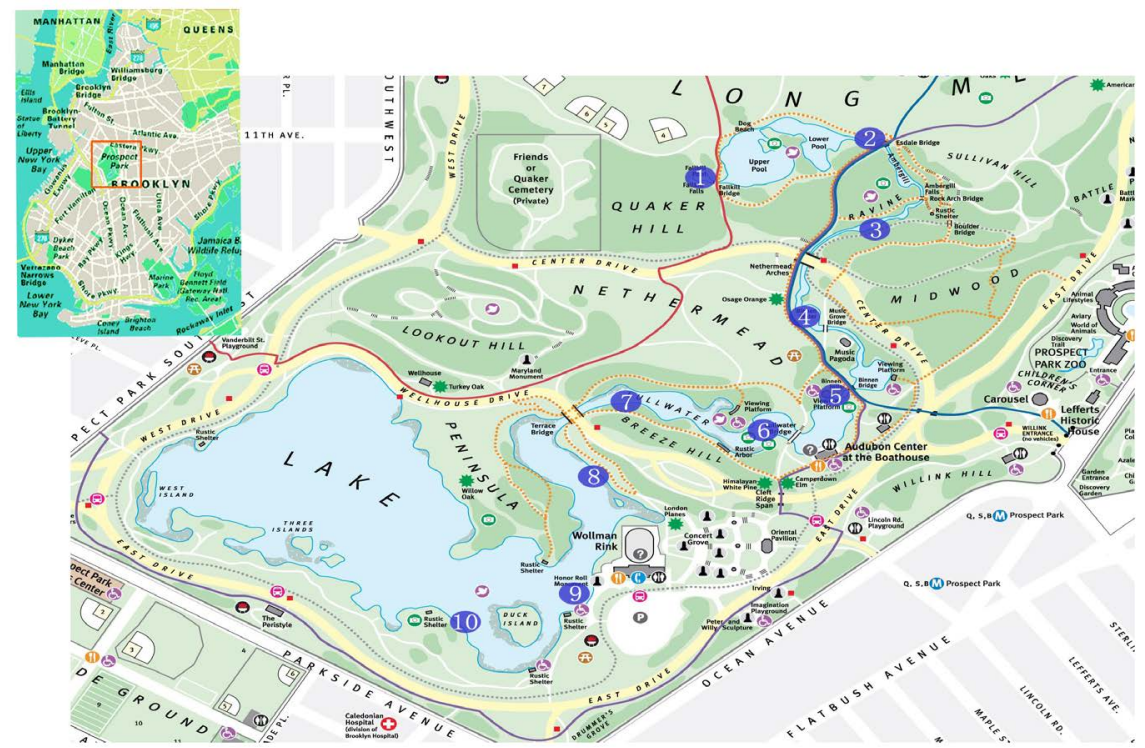

Figure 1. Sampling sites along the water system: municipal water flows in at site 1 and exits at the west end of the lower Pond as site 10 . 
ment can be reductively dissolved and phosphate adsorbed onto the surface of those compounds would then be desorbed and released into water. Water $\mathrm{pH}$ is also found important especially in sediments with a large proportion of Fe complex. As more hydroxyl ions will compete with phosphate ions for adsorption sites on the surface of the oxygenated Fe complex, increase of water $\mathrm{pH}$ in eutrophic lakes could potentially induce release of $\mathrm{PO}_{4}$ [9] [20] [21]. The release of $\mathrm{P}$ is not strictly an abiotic process, microbial processes and bioturbation could also impact the $\mathrm{P}$ circulation by impacting the sedimentation of organic matter and resuspension. These processes could be further complicated when coupling seasonal changes of water chemistry and the effects of primary production. Taking into account these complex interactions, it is necessary to couple the investigations of $\mathrm{P}$ in the water column and in the sediment simultaneously [16] [22] [23].

In this study, we investigated the water chemistry and sediment characteristics in a series of eutrophic ponds at the Prospect Park of Brooklyn, New York, USA. Phosphate in the water column was characterized to estimate the immediate availability to the algal growth and sediment was examined for $\mathrm{P}$ speciation to estimate potential mobility of sedimentary P. Temporal changes of Soluble Reactive Phosphate (SRP) along the flow were monitored from early spring to late summer and compared with relevant chemical parameters. The goal is to investigate the cycling of $\mathrm{P}$ among different pools of $\mathrm{P}$ and the role of these $\mathrm{P}$ in algal bloom. The majority of studies in the literature have focused on the cycling of $\mathrm{P}$ in a closed or semi-closed reservoir. Moreover, many studies on internal loading were based on operationally defined fractionation schemes and thus lack validation from in situ results. This study is one of the few trying to understand the cycling of $\mathrm{P}$ within a dynamic flow condition.

\section{Materials and Methods}

\subsection{Description of the Studied Sites}

This study was conducted in the serially connected, eutrophic ponds in Prospect Park, Brooklyn, New York $\left(40^{\circ} 39^{\prime} 39^{\prime \prime} \mathrm{N}, 73^{\circ} 57^{\prime} 56^{\prime \prime} \mathrm{W}\right)$. The ponds have a total surface area of 19.3 hectares. It is a uniformly shallow water body averaging 1.64 meters with a maximum depth of 2.3 meters. The source for the inflow is the New York City municipal water supply, to which orthophosphate is added since late 1990's to control corrosion and reduce the level of lead in drinking water. A total of 10 sites, one from each pond, were sampled. The flow is gravity driven, and starts from site 1 (Figure 1). While sites 1 - 4 are fenced area with limited access, sites 5 to 10 are all open to the public. Sites $5-7$ are the most eutrophic with blue green and green algae species. Sites 7 and 8 are the two largest ponds near the end of the water system. Among all these sites, sites 5 and 9 receive the most public visits.

\subsection{Sampling and Analytical Methods}

Surface water samples were collected at sites 1 to 10 along the water system 
(Figure 1) from mid-March to late August in 2008 every ten days. Conductivity, $\mathrm{pH}, \mathrm{ORP}, \mathrm{DO}$, turbidity and water temperature were measured in situ using a portable water quality monitor (Horiba). Chlorophyll a was measured using an UV spectrophotometer from methanol extracted glass fiber filters. Water samples were filtered upon collection for dissolved and particulate $\mathrm{P}$ analysis. $\mathrm{P}$ speciation followed EPA standard protocol [24]. Ammonia and nitrate in the water samples were measured using an Automated Discrete Nutrient Analyzer (Seal AQ2). Dissolved Fe, Ca, K and Mg were measured using an Elan DRC Inductively Coupled Plasma Mass Spectrometer (Perkin-Elmer).

Four bottom sediment grab samples were collected from two sites (5 and 9). Part of the sediment was freeze dried with a bench top $2.5 \mathrm{~L}$ freeze drying System (Labconco FreeZone), homogenized and stored in plastic bottles. The rest of sediment was oven dried and then calcinated at $550{ }^{\circ} \mathrm{C}$ for 2 hours in a furnace to calculate organic content by loss in ignition. Oven dried samples were then sieved and stored. Fine portion $(<200 \mu \mathrm{m})$ of oven-dried samples and freezedried samples were used for subsequent scanning by an X-ray Fluorescence Analyzer (Olympus Innov-X XRF) in triplicates for concentrations of major elements.

Speciation of $\mathrm{P}$ in the freeze-dried sediment samples was carried out according to the improved SMT protocol to determine $\mathrm{P}$ forms in freshwater sediments by Ruban et al. [12], modified from the Williams Method [11]. This extraction scheme was adopted due to its good reproducibility and it was practically easy to perform. The following fractions of $\mathrm{P}$ were determined: Inorganic $\mathrm{P}$ (IP) was extracted directly using $1 \mathrm{~mol} / \mathrm{L} \mathrm{HCl}$ for 16 hours, and the residue was calcinated and extracted again to determine organic $\mathrm{P}(\mathrm{OP})$. For NaOH-P (NaOH extracted $\mathrm{P})$ and $\mathrm{HCl}-\mathrm{P}(\mathrm{HCl}$ extracted $\mathrm{P})$, freeze dried sediment was first directly extracted by $1 \mathrm{~mol} / \mathrm{L} \mathrm{NaOH}$ for 16 hours. After that the supernatant was extracted again by $3.5 \mathrm{~mol} / \mathrm{L} \mathrm{HCl}$ for $\mathrm{NaOH}-\mathrm{P}$, and the residue was extracted again by 1 $\mathrm{mol} / \mathrm{L} \mathrm{HCl}$ for $\mathrm{HCl}-\mathrm{P}$. In this protocol $\mathrm{NaOH}-\mathrm{P}$ represents the exchangeable $\mathrm{P}$ mainly bound to $\mathrm{Fe} / \mathrm{Al}$ complex. $\mathrm{HCl}-\mathrm{P}$ is comparable to $\mathrm{P}$ mainly bound to $\mathrm{Ca}$ compounds. The total $\mathrm{P}$ is calculated as the sum of IP and OP.

\section{Results}

\subsection{Characteristics of Pond Water}

Chemical compositions of surface water during the 6-month sampling periods are shown in Table 1. Surface waters were all super-saturated with dissolved oxygen (i.e., $>7 \mathrm{mg} / \mathrm{L}$ ) and ORP were generally high for surface water samples. Chlorophyll a (Chl a) as an indicator of algal biomass ranged from $7.5-15 \mu \mathrm{g} / \mathrm{L}$ at these sites, indicating the eutrophic state. Dissolved Fe levels gradually increased along the flow from around $50 \mu \mathrm{g} / \mathrm{L}$ upstream to hundreds downstream.

Nitrate concentrations in August fluctuated between $30-120 \mu \mathrm{g} / \mathrm{L}$ at the upstream sites and dropped to less than $15 \mu \mathrm{g} / \mathrm{L}$ at site 7 and afterwards. Ammonia levels in August were low $(<75 \mu \mathrm{g} / \mathrm{L})$ before downstream ponds, increased to over $300 \mu \mathrm{g} / \mathrm{L}$ at site 8 and dropped rapidly thereafter. The low nitrate levels in- 
dicate $\mathrm{N}$ as the limiting nutrient here.

\subsection{P Speciation in the Water Column}

Figure 2 shows the result of $\mathrm{P}$ speciation (both dissolved and particulate) in the water column at sites 5 and 8 with samples collected in August, 2008. The partition pattern indicates the dominant $\mathrm{P}$ form within the water at both sites was dissolved orthophosphate or SRP, followed by dissolved organic-P and insoluble ortho-P (bound to particulate). The total $\mathrm{P}$ at site 5 almost doubles that of site 8 . While SRP is more dominant at site 5 than site 8, with SRP concentration of 150 $\mu \mathrm{g} / \mathrm{L}$ at site 5 and $50 \mu \mathrm{g} / \mathrm{L}$ at site 8 . Organic $\mathrm{P}$ (dissolved and insoluble) is slightly higher at site 8 than site 5 .

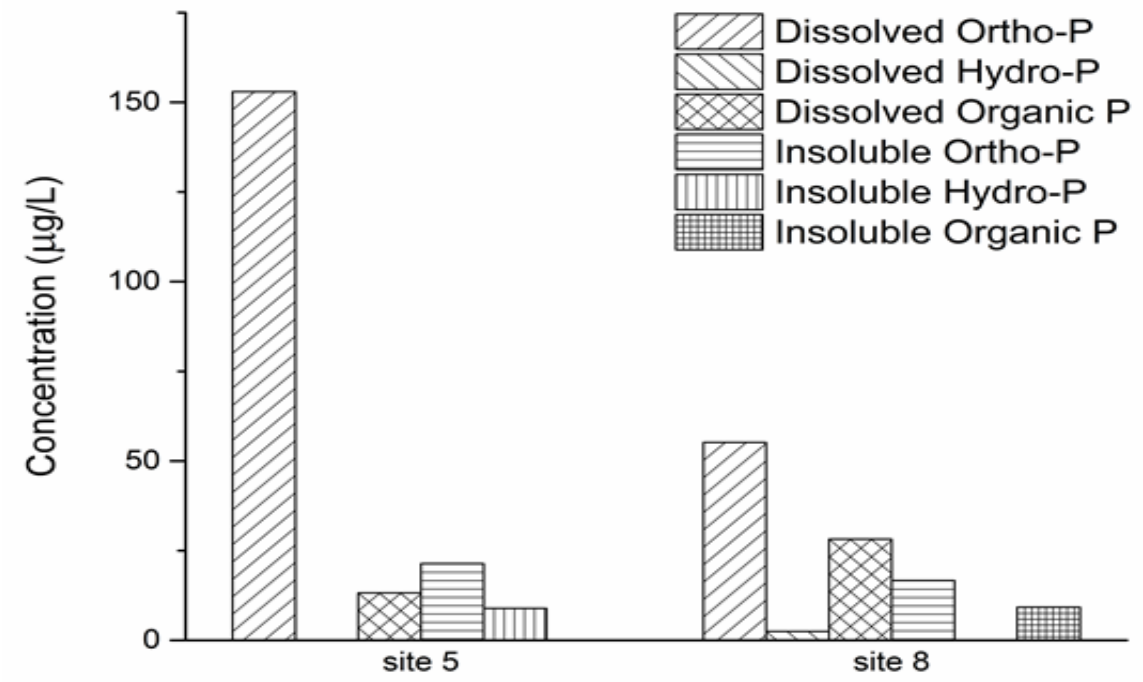

Figure 2. Speciation of dissolved and particulate P.

Table 1. Surface water chemistry of prospect park ponds.

\begin{tabular}{cccc}
\hline & \multicolumn{3}{c}{ Flow } \\
\cline { 2 - 4 } & $\begin{array}{c}\text { Upstream } \\
(\text { site } 1-3)\end{array}$ & $\begin{array}{c}\text { Midstream } \\
(\text { site } 4-7)\end{array}$ & $\begin{array}{c}\text { Downstream } \\
(\text { site } 8-10)\end{array}$ \\
\hline $\mathrm{pH}$ & $6.2-6.8$ & $6.9 \rightarrow 8.3$ & $6.3-7.6$ \\
Conductivity $(\mathrm{mS} / \mathrm{m})$ & $10-17$ & $17-20$ & $\sim 20$ \\
Turbidity $(\mathrm{NTU})$ & $17-30$ & $17-38$ & $20-25$ \\
$\mathrm{Chl} \mathrm{a}(\mu \mathrm{g} / \mathrm{L})$ & $3.5-6$ & $7.5-15$ & $6-13$ \\
ORP $(\mathrm{mV})$ & $347-560$ & $233-324$ & $229-261$ \\
$\mathrm{DO}(\mathrm{mg} / \mathrm{L})$ & $8.2-9.5$ & $8.2-10.0$ & $7.1-8.0$ \\
$\mathrm{Nitrate}(\mu \mathrm{g} / \mathrm{L})$ & $30-120$ & $15-70$ & $8-22$ \\
$\mathrm{Ammonia}(\mu \mathrm{g} / \mathrm{L})$ & $0-76$ & $62-154$ & $162-310$ \\
$\mathrm{Fe}(\mu \mathrm{g} / \mathrm{L})$ & $53-62$ & $81-156$ & $98-231$ \\
$\mathrm{Ca}(\mathrm{mg} / \mathrm{L})$ & $5.1-7.6$ & $7.4-10.1$ & $8.4-8.7$ \\
$\mathrm{Mg}(\mathrm{mg} / \mathrm{L})$ & $1.1-1.6$ & $1.6-2.5$ & $\sim 1.7$ \\
\hline
\end{tabular}




\subsection{Sedimentary P Fractionation}

The sediments were mainly silt, with an average total organic content of $13 \%$. XRF results show Ca concentrations were $5.1 \mathrm{mg} / \mathrm{g}$ and $4.0 \mathrm{mg} / \mathrm{g}$ at sites 5 and 9 , and $\mathrm{Fe}$ concentrations were 10 and $24 \mathrm{mg} / \mathrm{g}$ at sites 5 and 9 , respectively.

Sedimentary P fractionation results are shown in Figure 3. The TP levels at site 5 averaged $0.92 \mathrm{mg} / \mathrm{g}$ of dry sediment, slightly higher compared to $0.76 \mathrm{mg} / \mathrm{g}$ at site 9. In general, inorganic phosphorus (IP) was the dominant fraction of $\mathrm{P}$ in sediment, with NaOH-P the main components of IP. IP accounted for $62 \%$ to $80 \%$ of the total $\mathrm{P}$ (TP) in the sediment. $\mathrm{NaOH}-\mathrm{P}$, the exchangeable portion of $\mathrm{P}$ and mostly associated with Fe hydroxides, was found as the dominant $\mathrm{P}$ fraction at both sites. Although the TP levels at site 5 averaged $0.92 \mathrm{mg} / \mathrm{g}$ of dry sediment, slightly higher compared to $0.76 \mathrm{mg} / \mathrm{g}$ at site 9 , the fraction of $\mathrm{NaOH}-\mathrm{P}$ at site 9 was higher than that of site 5. The $\mathrm{HCl}-\mathrm{P}$, representing $\mathrm{P}$ associated with $\mathrm{Ca}$ complex as $\mathrm{Ca}-\mathrm{P}$, was only present at very low levels at all the studied sediment samples.

\subsection{Soluble Reactive Phosphate along the Flow}

Figure 4 compares trends of SRP along the water system from early spring to late summer. There is a general decreasing trend from upper ponds to lower ponds for the entire sampling season, with slight exception in August. The trend suggested that dissolved phosphate was gradually removed from the water column either to the sediment pool or by the biomass. Although the SRP levels at site 10 was still high and the pond was clearly eutrophic, algal bloom in early spring only occurred sparingly by observation. The sharp decrease of SRP at the last three ponds in the spring suggested larger quantities of phosphate in these ponds downstream were probably retained by the sediment than the biomass, comparing to sites 1-7.

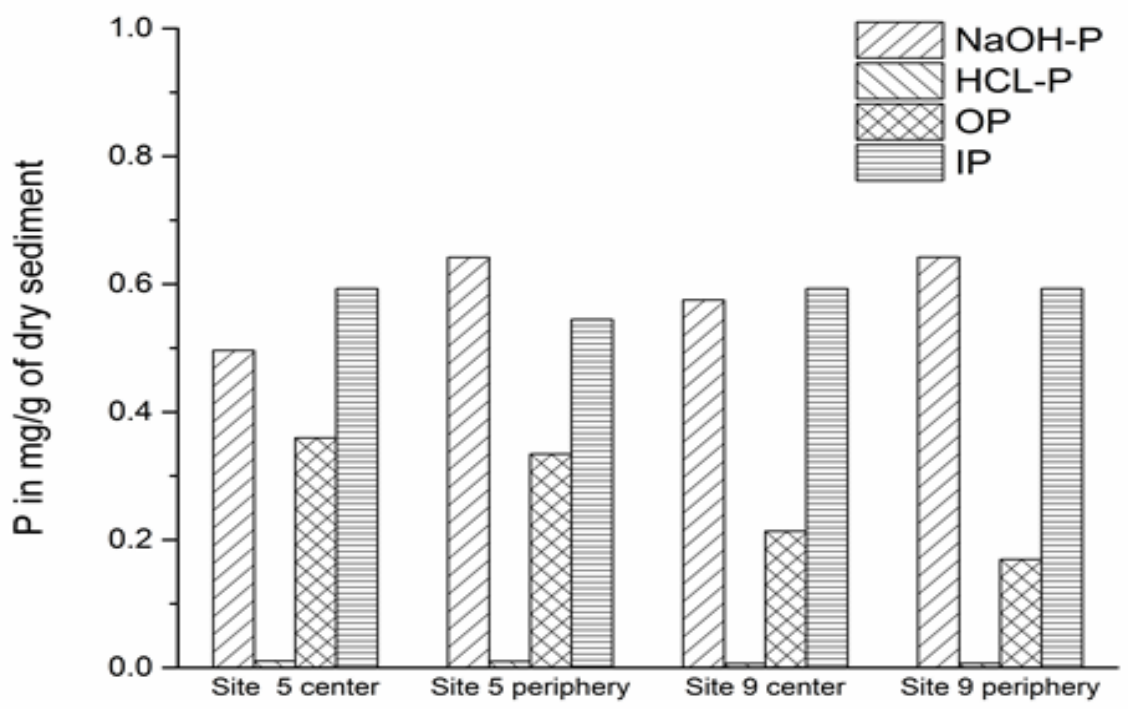

Figure 3. P speciation in sediment. Samples were taken from different locations of site 5 and 9. 


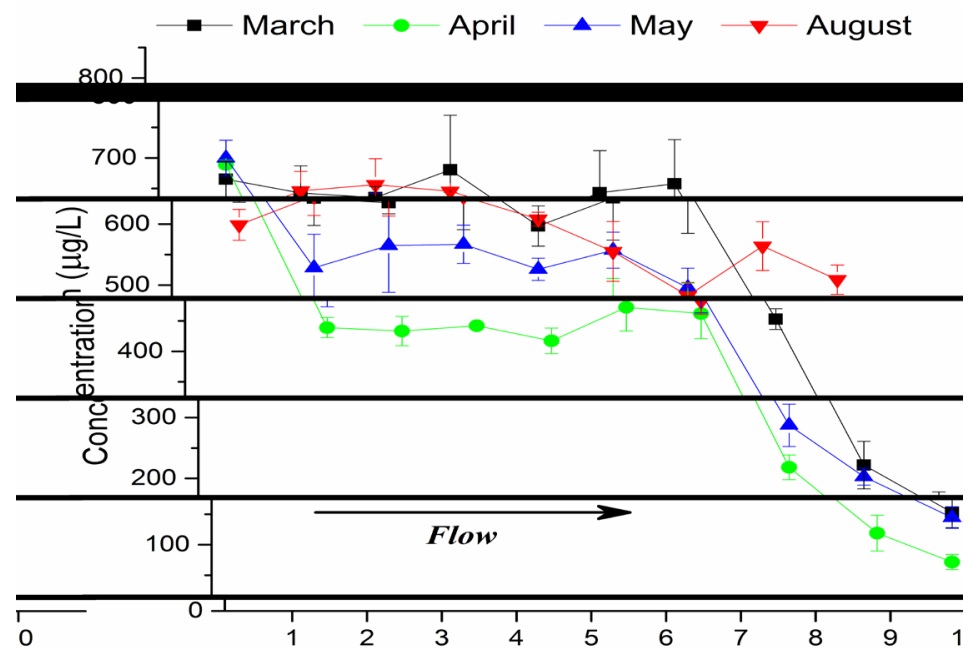

Figure 4. Soluble reactive phosphate (SRP) levels along with the flow (monthly average)

SRP in May has a similar trend to that of March/ April from site 1 to site 6 . SRP at site 7 was about $100 \mu \mathrm{g} / \mathrm{L}$ lower than at site 6 in May, probably due to the uptake by algal bloom which was generally considered to appear in May or late spring [9]. This was also consistent with the observed peaks of chlorophyll a of $\sim 15 \mu \mathrm{g} / \mathrm{L}$ at site 7 (Table 1) and high levels of turbidity (peaked at $38 \mathrm{NTU}$ ).

\subsection{Temporal Changes of Soluble Reactive Phosphate}

Comparing patterns of SRP levels at different months, it can be found that except for site 1 with the similar starting level of SRP, the SRP values are the highest in March, followed a significant decrease in April (Figure 4). Then the SRP levels kept increasing in May and reach the highest levels in August. The lower SRP levels in April than March could be attributed to the uptake of SRP by biomass from the water column during the mid-spring bloom. The slight increase in temperature could also stimulate the mineralization of suspended particles on which $\mathrm{PO}_{4}$ is sequestered. Since the uptake of biomass could also lower the SRP levels in early summer, the most probable explanation for the increase of SRP from May to August is the release of SRP from sediment-i.e., the internal loading of $P$.

\section{Discussions}

\subsection{More indications on Internal Loading}

Dissolved oxygen depth profiles in the water column were also determined (data not shown) at selected sites. Surface waters were all saturated with dissolved oxygen and the DO level increased gradually along the waterway, with the highest super-saturation at site 9. Near the bottom of the water column DO level dropped to $3.4 \mathrm{mg} / \mathrm{L}$ at the 1.5 -meter depth at site 9 in August, much lower than that of the surface water and close to hypoxia. Although the shallow nature of the ponds would limit the occurrence of stratification in the summer, hypoxia could still happen near the sediment-water interface due to the presence of algal 
bloom-which reduces water circulation and oxygen diffusion.

The temporal trends of total dissolved $\mathrm{Fe}$ and $\mathrm{P}$ are very similar during the entire sampling period (Figure 5). SRP correlates well with Fe levels $\left(\mathrm{R}^{2} \approx 0.80, \mathrm{~N}\right.$ $=12$ ). There is also good correlation with $\mathrm{pH}$ of the surface water: when the $\mathrm{pH}$ increased, the $\mathrm{Fe}$ and $\mathrm{P}$ levels increased accordingly or soon after. The $\mathrm{pH}$ increase at the surface is usually caused by photosynthesis of algal biomass, while the coupled increase of Fe and P in the water column is an indication of the dissolution of Fe-hydroxides and the release of adsorbed phosphate from the sediment. Such dissolution of Fe-hydroxides can happen under reducing environment, which is known to exist in organic rich lake bottom sediments. The reduced oxygen levels at the bottom of the pond will enhance the reducing environment in the sediment matrix. And more $\mathrm{Fe}$ and phosphate will be released and diffused into the water column.

\subsection{Mobility of Sedimentary Phosphate}

The sedimentary $\mathrm{P}$ speciation in the sediment is consistent with significant internal loading of $\mathrm{P}$ from the sediment. Since most of phosphate in the sediment was present as $\mathrm{NaOH}-\mathrm{P}$, the high levels of labile $\mathrm{P}$ adsorbed on Fe-oxyhydroxides can be easily released under high water $\mathrm{pH}$ or lowered $\mathrm{DO}$ and nitrate conditions at the bottom of the water column. Increased microbial decomposition can also accelerate such release. This internal loading is more significant at ponds in the second half of the water system, where the pond areas are much larger and water is deeper. For sites 1 - 4 the ponds had shorter residence time, thus phosphate levels in the water column would be more controlled by the municipal input and contributions from internal loading appears less important.

An estimate of the sediment $\mathrm{P}$ stock is made based on the results from site 5 . Considering that the total area of the ponds is approximately 19.3 hectares, $\mathrm{P}$ adsorption/desorption is active in the upper $5 \mathrm{~cm}$ of the sediment, with a mean

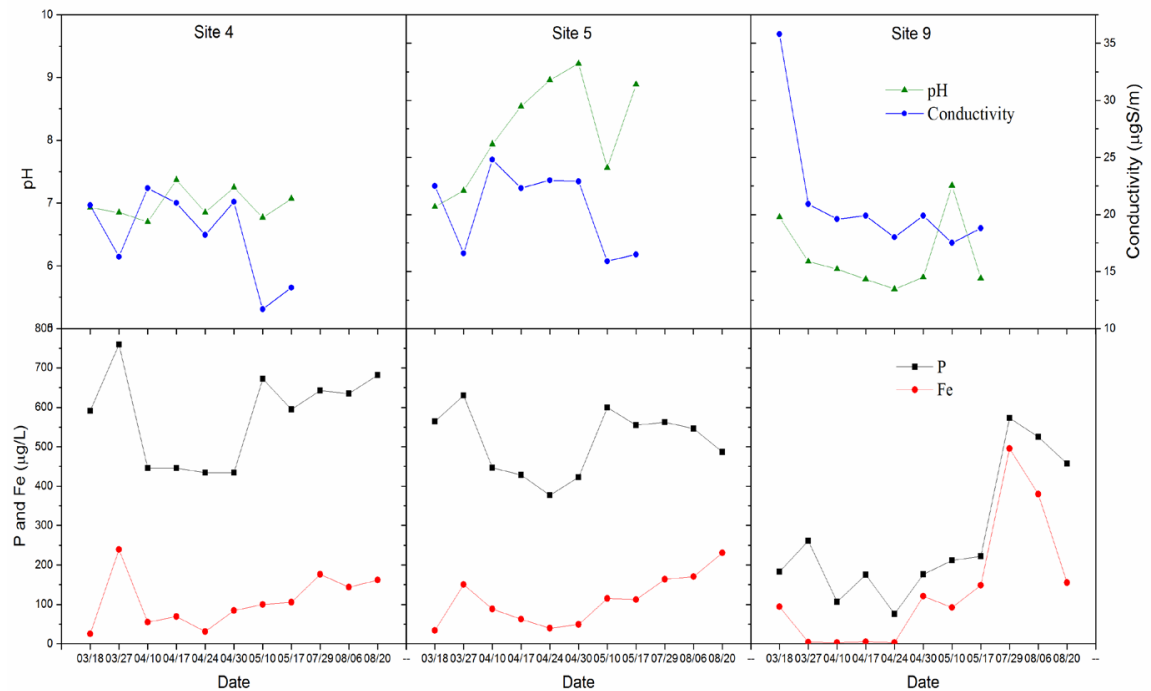

Figure 5. Temporal changes of $\mathrm{pH}$ and conductivity, total dissolved $\mathrm{P}$, and Fe concentrations at Sites 4, 5 and 9. 
sediment water content of $74 \%$, and assuming the bulk density of the sediment as $\sim 1.1$ grams per $\mathrm{cm}^{3}$ [25], the dry mass of sediment was roughly 2760 metric tons. The mass of $\mathrm{NaOH}-\mathrm{P}$ and organic $\mathrm{P}$ were thus $\sim 1885$ metric tons and 848 metric tons, respectively. The total stock of labile $\mathrm{P}$ is thus extraordinarily large and cannot be neglected. However, it should be noted that the contribution from internal loading is dependent upon conditions in each pond and therefore can vary.

\section{Conclusions}

It is found that in Prospect Park, the most abundant P form in the water column is dissolved ortho-phosphate, which was gradually removed from the water column and deposited in the sediment throughout the water system. The sequestering of the orthophosphate can be direct adsorption onto Fe-oxyhydroxides in the sediment in oxygenated water, and the annual precipitation of dead algal biomass to the bottom of the ponds.

Correlated levels of dissolved Fe and SRP in the water column indicated significant amount of $\mathrm{P}$ were released from the sediment. Temporal variations of SRP suggested that the algal bloom and proliferation of macrophytes impact internal loading through several processes that generally enhance the release of $\mathrm{P}$ from the iron rich sediment in late spring-summer-early fall season. Sedimentary $\mathrm{P}$ results show the dominance of $\mathrm{NaOH}-\mathrm{P}$, which is consistent with high potential of internal $\mathrm{P}$ loading from the sediment. The large pool of sedimentary $\mathrm{P}$ resulted from chronic external loading should not be neglected when developing effective restoration plans for long-term sustainability.

It is predictable that without the elimination of existing external $\mathrm{P}$ input from the municipal water, common in-lake restoration strategies would be limited in their effectiveness. Considering the large stock of sedimentary P, spot dredging is one of the few techniques that could alleviate symptoms in the water system. The removal of the organic and nutrient rich top sediment layer may significantly lower the nutrient levels and reduce the blooms when external source could be adequately reduced [26]. However, the potential merits of dredging are often limited by the high cost. A sound nutrient budget is in urgent need before the implement of any water restoration strategy. More specific field monitoring and mesocosm experiments studying the various aspects of possible internal loading processes are needed to better understand these complex processes.

\section{Acknowledgements}

The authors want to thank the Prospect Park Alliance for providing access and assistance in water and sediment sampling. Special thanks to Ms. Ann Wong and Mr. John Jordan for logistics and background information of the park.

\section{References}

[1] Shan, B., Li, J., Zhang, W., Di, Z. and Jin, X. (2016) Characteristics of Phosphorus Components in the Sediments of Main Rivers into the Bohai Sea. Ecological Engi- 
neering, 97, 426-433.

https://doi.org/10.1016/j.ecoleng.2016.10.042

[2] Conley, D.J., et al. (2009) Controlling Eutrophication: Nitrogen and Phosphorus. Science, 323, 1014-1015. https://doi.org/10.1126/science.1167755

[3] Smith, V.H. (2003) Eutrophication of Freshwater and Coastal Marine Ecosystems a Global Problem. Environmental Science and Pollution Research, 10, 126-139. https://doi.org/10.1065/espr2002.12.142

[4] Carpenter, S.R. (2008) Phosphorus Control Is Critical to Mitigating Eutrophication. Proceedings of the National Academy of Sciences of the United States of America, 105, 11039-11040. https://doi.org/10.1073/pnas.0806112105

[5] Correll, D.L. (1998) The Role of Phosphorus in the Eutrophication of Receiving Waters: A Review. Journal of Environmental Quality, 27, 261-266. https://doi.org/10.2134/jeq1998.00472425002700020004x

[6] Schock, M.R. (1996) Corrosion Inhibitor Applications in Drinking Water Treatment: Conforming to the Lead and Copper Rule. CORROSION '96: National Association of Corrosion Engineers (NACE) Conference, Denver, 24-29 March 1996.

[7] Bloomberg, M.R. and Lawitts, M.S.W. (2005) New York City 2008 Drinking Water Supply and Quality Report. http://www.nyc.gov/html/dep/pdf/wsstat05.pdf

[8] Blasio, B. and Sapienza, V. (2010) New York City 2010 Drinking Water Supply and Quality Report. http://www.nyc.gov/html/dep/pdf/wsstate16.pdf

[9] Søndergaard, M., Jensen, J.P. and Jeppesen, E. (2003) Role of Sediment and Internal Loading of Phosphorus in Shallow Lakes. Hydrobiologia, 506, 135-145.

https://doi.org/10.1023/B:HYDR.0000008611.12704.dd

[10] Jeppesen, E., et al. (1991) Recovery Resilience Following a Reduction in External Phosphorus Loading of Shallow, Eutrophic Danish Lakes: Duration, Regulating Factors and Methods for Overcoming Resilience. Memorie dell'Istituto Italiano di Idrobiologia, 48, 127-148.

[11] Williams, J.D.H., Jaquet, J.M. and Thomas, R.L. (1976) Forms of Phosphorus in the Surficial Sediments of Lake Erie. Journal of the Fisheries Board of Canada, 33, 413-429. https://doi.org/10.1139/f76-063

[12] Ruban, V., et al. (1999) Selection and Evaluation of Sequential Extraction Procedures for the Determination of Phosphorus Forms in Lake Sediment. Journal of Environmental Monitoring, 1, 51-56. https://doi.org/10.1039/a807778i

[13] Ruttenberg, K.C. (1992) Development of a Sequential Extraction Method for Different Forms of Phosphorus in Marine Sediments. Limnology and Oceanography, 37, 1460-1482. https://doi.org/10.4319/lo.1992.37.7.1460

[14] Psenner, R. and Pucsko, R. (1988) Phosphorus Fractionation: Advantages and Limits of the Method for the Study of Sediment P Origins and Interactions. Archiv für Hydrobiologie. Beihefte. Ergebnisse der Limnologie, 30, 43-60.

[15] Stumm, W. and Morgan, J.J. (1981) Aquatic Chemistry: An Introduction Emphasizing Chemical Equilibria in Natural Waters. 2nd Edition, John Wiley \& Sons Ltd., New York.

[16] Golterman, H.L. (1996) Fractionation of Sediment Phosphate with Chelating Compounds: A Simplification, and Comparison with Other Methods. Hydrobiologia, 335, 87-95. https://doi.org/10.1007/BF00013687

[17] Golterman, H.L. (1982) Differential Extraction of Sediment Phosphates with Nta Solutions. Hydrobiologia, 91, 683-687. https://doi.org/10.1007/BF02391983

[18] Mortimer, C.H. (1941) The Exchange of Dissolved Substances between Mud and Water in Lakes. Journal of Ecology, 29, 280-329. https://doi.org/10.2307/2256395 
[19] Boström, B., Andersen, J.M., Fleischer, S. and Jansson, M. (1988) Exchange of Phosphorus across the Sediment-Water Interface. Hydrobiologia, 170, 229-244. https://doi.org/10.1007/BF00024907

[20] Lijklema, L. (1977) Role of Iron in the Exchange of Phosphate between Water and Sediments. In: Golterman, H.L., Ed., Interactions between Sediments and Fresh Water. Proceedings of an International Symposium, Amsterdam, 313-323.

[21] Koski-Vähälä, J. and Hartikainen, H. (2001) Assessment of the Risk of Phosphorus Loading Due to Resuspended Sediment. Journal of Environmental Quality, 30, 960-966. https://doi.org/10.2134/jeq2001.303960x

[22] Williams, J.D.H., Jaquet, J.M. and Thomas, R.L. (1976) Forms of Phosphorus in the Surficial Sediments of Lake Erie. Journal of the Fisheries Research Board of Canada, 33, 413-429. https://doi.org/10.1139/f76-063

[23] De Vicente, I., Serrano, L., Amores, V., Clavero, V. and Cruz-Pizarro, L. (2003) Sediment Phosphate Fractionation and Interstitial Water Phosphate Concentration in Two Coastal Lagoons (Albuferas De Adra, SE Spain). Hydrobiologia, 492, 95-105. https://doi.org/10.1023/A:1024813811763

[24] Zimmermann, C., Keefe, C. and Bashe, J. (1997) Determination of Orthophosphate in Estuarine and Coastal Waters by Automated Colorimetric Analysis. In: Methods for the Determination of Chemical Substances in Marine and Estuarine Environmental Matrices, US Environmental Protection Agency, Washington DC.

[25] Fitzpatrick, W.P. (1987) Sedimentation Survey of Dawson Lake, Moraine View State Lake, Mclean County, Illinois. Illinois State Water Survey Contract Report, 413, $1-25$.

[26] Van der Does, J., et al. (1992) Lake Restoration with and without Dredging of Phosphorus-Enriched Upper Sediment Layers. Hydrobiologia, 233, 197-210. https://doi.org/10.1007/BF00016108

\section{Submit or recommend next manuscript to SCIRP and we will provide best} service for you:

Accepting pre-submission inquiries through Email, Facebook, LinkedIn, Twitter, etc. A wide selection of journals (inclusive of 9 subjects, more than 200 journals)

Providing 24-hour high-quality service

User-friendly online submission system

Fair and swift peer-review system

Efficient typesetting and proofreading procedure

Display of the result of downloads and visits, as well as the number of cited articles

Maximum dissemination of your research work

Submit your manuscript at: http://papersubmission.scirp.org/

Or contact gep@scirp.org 